\title{
Rethinking human trafficking in Southeast Asia to better reflect survivors' agency
}

Edition 8, 2021

Dr Guangyu Qiao-Franco

DOI: 10.37839/MAR2652-550X8.12

Trafficked persons are usually motivated to leave their home countries to escape poverty, discrimination or violence and become involved in situations where they experience uncertain legal status and exploitative work practices.

However, trafficked persons also exercise a great deal of agency which is often overlooked by current international anti-trafficking legal frameworks, which can disempower trafficked persons by categorising them as simply 'victims'.

I argue this situation can change if trafficked persons are understood through contemporary understandings of transnationalism; that is, people engaging in crossborder travel and maintaining contacts on a sustained basis. From a transnationalism lens, it is possible to see the process of survivors transitioning away from trafficking and reconstructing their agency by seeking economic, political, social and cultural links with their countries of origin.

\section{Human trafficking is a persistent challenge in Southeast Asia}

Reliable data on human trafficking are inherently limited due to the clandestine nature of the issue, but the International Organisation for Migration (IOM) reports to have rescued or assisted 17,171 trafficked persons originating from the Asia Pacific 
between 2002 and 2019, accounting for 35 percent of the total number of worldwide cases documented in this period.

Estimates of the numbers of irregular migrants in Malaysia and Thailand, which are two major receiving countries within Southeast Asia, are in the millions and a significant proportion of these irregular migrants are thought to include people trafficked for forced labour, indentured servitude, and sexual exploitation. Similar to other regions, trafficked persons from Southeast Asia are typically 'pushed' by factors such as poverty, unemployment, natural disasters, instability or war, and gender-related discrimination in source countries; and 'pulled' by perceived socioeconomic opportunities in destination countries.

Southeast Asian countries have improved cross-border coordination to address human trafficking, including enacting a legally binding regional instrument in 2015, the ASEAN Convention Against Trafficking in Persons, Especially Women and Children (ACTIP). ACTIP and its plan of action-like the vast number of reports, policies and research published by state governments, international organisations, and non-governmental organisations (NGOs) in the last two decades-are based on a concept of trafficking that posits trafficked persons as helpless victims forced into dire situations. Article 2.a of ACTIP, defines 'trafficking in persons' as:

'...the recruitment, transportation, transfer, harbouring or receipt of persons, by means of the threat or use of force or other forms of coercion, of abduction, of fraud, of deception, of the abuse of power or of a position of vulnerability or of the giving or receiving of payments or benefits to achieve the consent of a person having control over another person, for the purpose of exploitation. Exploitation shall include, at a minimum, the exploitation of the prostitution of others or other forms of sexual exploitation, forced labour or services, slavery or practices similar to slavery, servitude, or the removal of organs.' (Article 2.a)

Consistent with the United Nations Protocol to Prevent, Suppress and Punish Trafficking in Persons, Especially Women and Children, ACTIP defines child 
trafficking as the 'recruitment, transportation, transfer, harbouring or receipt of a child for the purpose of exploitation' regardless of the means used (Article 2.c).

This definition represents trafficked persons as largely passive and helpless 'victims' coerced or deceived to move because they are young, naïve, vulnerable, and thus in need of rescue and reintegration. Without denying that trafficked persons need protection, real-life circumstances are much more complicated.

Trafficked persons who are completely restricted in decision-making and movement are extreme cases that likely represent only a small fraction of trafficking cases within the region. Most are motivated migrants, caught somewhere on a scale of debt and exploitative working/living conditions, trying to negotiate with recruitment agencies and employers, and making the best of tough situations. To portray them simply as victims, we risk failing to recognise that they are capable of making independent decisions.

Furthermore, empirical evidence points to the existence of sustained economic, political, social and cultural transnational practices among trafficked persons, which are characteristic of transnationalism. Transnationalism has become a key field of study in international migration since the late 1990s. It denotes the phenomenon where a significant number of people engage in 'cross-border travel and contacts on a sustained basis', as mentioned earlier. The literature on transnationalism is essential to the acknowledgement of migrants' contributions to both countries of destination and countries of origin. However, the current theorisation of transnational communities and practices is mainly grounded in accounts of regular migration and has excluded discussions of trafficking survivors.

In this article, I re-evaluate counter-trafficking initiatives in Southeast Asia through the lens of transnationalism. This perspective is important because it recognises and respects the capacity of vulnerable groups to engage in transnational activities instead of treating them as objects of intervention. While in no way wishing to discount the ordeals that many trafficked persons have suffered-including unsafe 
work conditions, malnutrition, substance abuse, sexual violence, slavery and imprisonment-I do want to shed light on the evidence that speaks to their capacity to control decision-making and partake in transnational activities. This new evaluation will hopefully contribute to a reassessment of our ethical responsibilities to trafficking survivors that takes increasing account of their resilience beyond their vulnerability.

\section{Helpless victims or capable transnational actors?}

In Southeast Asia, a long tradition of labour migration predates colonial times and has been shaped by complex social, economic and political factors. While regional countries have worked to ease legal restrictions on migration since the 1980s, the relevant policies remain too restrictive in view of the large pool of low-skilled labourers that are eager to leave poverty-stricken situations in their home nations for better employment opportunities. As a result, many individuals turn to illegal channels to migrate or find work abroad. Meanwhile, many sectors in relatively developed areas within the region, such as fishing and rubber plantations, continue to rely on the employment of temporary migrant workers to meet labour demand.

These 'push' and 'pull' factors all contribute to the growth of regular and irregular movements of people, which feed trafficking networks. Many people seeking to migrate overseas experience deceptive and exploitative brokerage practices. Once in the country of destination, they may find themselves in abusive work and living situations and some may fall victim to trafficking. Undeniably, most trafficked women, men and children have suffered incredible ordeals. However, my examination of the narratives of trafficking survivors in this article demonstrates, just like labour migrants, trafficked persons are resilient actors that exercise a great deal of agency.

Many trafficked persons are highly motivated to migrate in search of a better life. 
For those facing poverty, persecution, armed conflict and environmental disasters, legal migration channels may be impossible to access. Being smuggled or seeking work through unscrupulous brokers may thus be the 'best' or a 'reasonable' option. As Maria, a trafficking survivor from the Philippines, said:

'I was aware of the risks and dangers of working abroad. And I have heard of incidents of unresolved mysterious deaths of overseas Filipino workers, of slain mailorder brides, of abuses and exploitation of women, and of human trafficking. But that didn't stop me... If I had stayed, who would feed my family? My remittance brings them food and hope.'

Survivors' narratives not only attest to their agency in initiating the journey, but also their ability to cope with difficult situations along the way. Trafficking is certainly an unintended consequence of these survivors' decision to migrate. However, some trafficked people do not find their circumstances as dire as rights advocates and news media would have the public to believe. Interviews with trafficking survivors in Cambodia by social work scholar Laura Cordisco Tsai and others show that many did not see themselves as abused and, on the contrary, earned money and sent remittances home to support sick parents, younger siblings or their own children despite difficult times. This view is shared by many studies on trafficking in nonSoutheast Asian contexts, where trafficking sufferers exhibited skills and capacity to strive for better situations such as negotiating with employers, foster families, and traffickers.

There are also cases indicating that despite experiences of being mistreated and insufficiently compensated, some migrant workers still chose to stay with their employers. The story of Puthy as reported by the Phnom Penh Post is an example. Puthy has repeatedly journeyed back to Koh Kong province in Thailand despite being drugged, forced to work for days on a fishing vessel without sleep and beaten by police. But many young people like Puthy face poverty and a lack of opportunities at home. Without safer alternatives, they make the best decisions they can under the circumstances. Labelling them as victims has undoubtedly promoted greater public 
awareness of their situations and has led to a greater focus on protection. However, such labels have also had the consequence of denying agency to trafficked persons.

\section{Trafficked persons' contributions to incipient transnationalism}

The classic idea of trafficked persons as passive victims is woefully out of date, not only because of mounting evidence of their capacity to make decisions independently, but also because of their contribution to transnational activities. Many Southeast Asian governments have tried to maintain links with their diaspora, and thus encourage transnationalism where a significant number of their citizens are routinely involved in international activities and maintain contacts across borders. Transnational activities can be divided into several categories, including political (e.g., lobbying), economic (e.g., remittances and investment) and socio-cultural (e.g., cultural events that reinforce national identity abroad). However, trafficked persons have been largely excluded from discussions under this framework within policy and academic circles.

Overlooking trafficked communities in transnational studies risks ignoring the sizable body of research that questions the validity of the categorisation of trafficking, smuggling and labour migration. Dr Anne Gallagher, for instance, who led the development of the United Nations Principles and Guidelines on Human Rights and Human Trafficking contends that the distinction between 'forced' and 'voluntary' that separates trafficking from other categories of migration may belie the realities of migration decision-making: for at least some trafficked persons, migrating may initially or at some stage result from individual choice rather than from coercion. Research by Diana Wong and Michele Ford and others on trafficking in Southeast Asia also found that migrant workers were often trapped in a 'revolving door', whose status frequently changed between legal and illegal, forced and voluntary. The reasons for the changes include the brevity of work contracts, restrictive migration policies, the high costs of regular migration, widespread 
exploitative and oppressive practices by employers, and a lack of oversight in some countries. Therefore, it can be implied from this body of work that trafficked persons may have access to the networks and ways to connect with home countries that have been established by regular migrants.

Furthermore, empirical evidence from Southeast Asia indicates that traumatic experiences during trafficking may decrease the capacity of survivors to re-build links with family and friends. However, it may also constitute a powerful impetus to maintain contact with their home countries. First, the economic contributions of trafficking survivors to both countries of origin and destination should not be underestimated. Supporting family members is often a primary reason for migration in rural Southeast Asia. Despite difficult circumstances, many trafficked persons have been found to maintain contact with family members and remit a substantial part of their income. Recent IOM research suggests that remittances from lowskilled migrants are usually dispatched in response to specific requests from dependent family members and friends, covering basics such as food, clothing, utilities, rent, education and medical care. Across the borders of Myanmar and Thailand, remittance transfer has been institutionalised to replace traditional cashbased remittances, exemplified by the creation of the 'hundi system'. Through this system, recipients in Myanmar receive money from local remittance agents, after migrants pay remittances and services fees to the counterpart agency in Thailand. Beyond Myanmar and Thailand, the development of transnational money service businesses including remittance agents, foreign exchange dealers, and electronic money issuers, have facilitated sending earnings home.

The contributions of trafficked persons go beyond economic development to include the socio-cultural aspects such as sharing of ideas, cultures and rituals across countries. The hardships of living and working environments do not preclude trafficked persons fostering friendships with local peoples. These new local contacts help the establishment of transnational identities. Newly acquired ideas (such as gender norms) and practices (such as skills in sewing and construction) can be transferred to countries of origin through letters, phone calls, emails or home 
visits-a phenomenon known as 'social remittances'. Most notably, some returnees become advocates for the rights of the trafficking community itself. As an example, Ima Matul, an Indonesian survivor of domestic servitude for three years in the United States, has become an advocate for survivors of slavery and trafficking in Los Angeles.

In the political sphere, trafficked persons build solidarity among their colleagues and align with NGOs and international organisations to advocate for change in their countries of origin and destination. For instance, research by social scientist Stephen Campbell found that Burmese migrant workers in Thailand, including those in situations equivalent to trafficking, were able to organise collective action over 'shared workplace grievances' like long working hours and harsh working conditions. Some of these activities were facilitated by migrant worker support organisations. They not only applied pressure on host companies to improve the working environment for foreign workers but also fuelled discussions on the rights of migrant workers at the international level. Some of the more experienced migrant workers align with international NGOs and donors to lobby at domestic, regional and international levels. In this sense, they are agents of political change.

\section{Problematisation of current human trafficking legal frameworks}

There is no doubt that the financial constraints of trafficked workers, their lack of legal status, language barriers and limited rights (e.g. rights of coalition) can limit their ability to get involved in regular transnational activities. Trauma and stigma related to experiences of trafficking may also decrease willingness to re-build links with their home country. Without underestimating these issues, however, we cannot ignore their capacity to create appropriate strategies of response. But the current anti-trafficking laws and initiatives geared toward addressing human trafficking, including those implemented in Southeast Asia, have tended to further marginalise these individuals. 
Like most regions, Southeast Asia has embraced both criminal justice and human rights approaches to addressing human trafficking. The criminal justice approach includes measures to secure border controls and prosecute perpetrators. The human rights approach is centred on victim protection, which in comparison with the criminal justice approach places a higher emphasis on the security, human rights, and welfare of trafficked persons. That said, the rights-based approach embedded in victim protection measures has largely been pursued through rehabilitation in shelters-a process deemed integral to recovery and reintegration.

Who is considered as a victim and who is eligible for protection provided through shelters are decisions made by counter-trafficking entities such as government agencies and service providers. However, many trafficked people find their voices silenced or ignored in the name of their 'best interests' while interacting with these entities. Interviews with trafficking survivors from Cambodia, by Laura Cordisco Tsai and others indicate that many of them experience highly restricted movement, minimal contact with family members, and little power to determine the duration of their stay in destination countries. Some were repatriated to their countries of origin against their will. Typically, survivors' desire to earn money and maintain links with family members does not change once they are 'rescued' by law enforcement and non-state organisations. However, many service providers regard trafficked persons as helpless, naïve and dependent victims. This demonstrates a marked deviation from evidence outlined above that indicates the desire and capabilities of trafficking survivors to set their own agendas and experiences. Therefore, current countertrafficking efforts may risk being antithetical to the recovery and reintegration of trafficking sufferers.

\section{Accommodating survivors' agency and resilience within human trafficking}




\section{interventions}

It is not my intention to advocate abandoning border security and victim protection measures altogether. But a transnationalism perspective on trafficking could be a constructive supplement to current legal frameworks. It reconceptualises trafficked persons in a more positive light, which not only incorporates a labour rights perspective that respects their human rights but also acknowledges their skills and capabilities that can make them an asset to both countries of origin and destination.

From a transnationalism perspective, trafficking is less about innocent victims than it is about the realities of migration: the imperative, and therefore the desire, to migrate. Current anti-trafficking programs such as those described above should be complemented by measures to streamline labour migration and improve the situation of migrant workers. Good practices in the region show that reducing legal restrictions on migration for labour, making work permits more accessible, prohibiting recruitment fees, wage protection, and introducing complaint mechanisms, skills training and other measures, can help address trafficking at its source.

Alongside these long-term strategies, measures to address human trafficking should be empowerment-based to enable trafficked persons to meet their priorities and needs. There has been an array of good practices established by international agencies in this respect. For instance, IOM in Thailand has been engaged in providing survivors with microfinance for small businesses, training in business development and job counselling. Unfortunately, such measures are provided with a tiny fraction of the resources allocated to trafficking, in inverse proportion to their importance. It is imperative to provide more enabling services that take into account survivors' resilience and agency. This includes consulting with survivors when designing policy responses and supporting services so they can be better empowered to reconstruct their post-trafficking lives after they leave assistance programs. 
This empowerment-based approach does not detract from the importance of providing protection services to help survivors recover from traumatic experiences. However, I argue it is crucial to consider the diverse experiences and circumstances of people's lives without necessarily labelling and identifying a trafficked person as a victim only. Such framings reinforce their marginalisation and disempowerment. A conceptual shift that rethinks trafficking through the lens of transnationalism is a constructive step towards the full appreciation of the multitude of experiences of trafficking survivors.

Image: A fisher in Thailand. Credit: ILO/Flickr. 